\title{
Correspondence
}

\section{Blue paraffin wax blocks: a solution to the problem}

Thick slices of tissue can readily be stained with Mayer's haematoxylin. The ability to study tissue blocks 1000 to $3000 \mu \mathrm{m}$ deep after initial examination with conventional $5 \mu \mathrm{m}$ sections seems likely to increase the use of the method. ${ }^{1}$ However, there remains a potential embarrassment for the practitioner of this technique, and possible frustration for those subsequently wishing to use the paraffin wax embedded material for the study of nuclear associated antigens. Return of tissue blocks to a referring pathologist with an unsightly dark blue hue, or overlaying of nuclei by retained haematoxylin, could prove counterproductive.

We have overcome both these problems with a simple procedure. The thick tissue slices are reprocessed with xylene and graded methanols from methyl salicylate or other clearing agents to isotonic $10 \%$ formaldehyde. ${ }^{1-3}$ The haematoxylin staining is then removed by:

(1) Immersion in running cold tap water for 30 minutes.

(2) Soaking in $2 \%$ acid alcohol for two hours at room temperature.
(3) Immersion in cold tap water for a further 15 minutes.

(4) Brief storage in formaldehyde before processing for re-embedding in paraffin wax and later sectioning at conventional depth.

The tissue slices become completely decolourised macroscopically (thus avoiding the embarrassment of returning "blue blocks"), and the haematoxylin staining is entirely removed from the block and subsequent $5 \mu \mathrm{m}$ paraffin wax sections (figure), thereby allowing any future nuclear immunohistochemistry to be unhindered by the previous haematoxylin staining. ${ }^{1}$ J KULKA Jegional Breast Pathology Unit, University of Bristol and the Wolfson Foundation, Bristol BS10 5NB
Bolfson Foundation,

1 Armstrong JS, Davies JD, Hronkova B. Backprocessing paraffin wax blocks for subgross examination. $f$ Clin Pathol 1992;45: 1116-7.

2 Leech S, Armstrong JS, Kulka J, Davies JD. Non-nuclear staining of thick tissue sections. $\mathcal{F}$ Clin Pathol 1993;46:780-1.

3 Davies JD, Kulka J, Mumford A, Armstrong JS, Wells CA. Hamartomas of the breast: six novel diagnostic features in three-dimensional thick sections. Histopathology (In press).

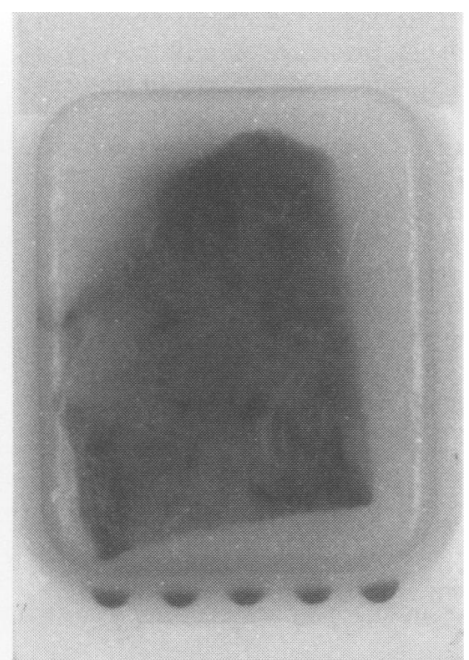

Paraffin wax blocks ( $2 \mathrm{~mm}$ deep) in processing cassettes showing dark blue haematoxylin staining after thick section examination (left), which is entirely removed after the 2 hour acid alcohol treatment (right).

\section{Benign familial hyperphosphatasaemia}

We were interested to read the paper of Rosalki et al ${ }^{1}$ which describes in great detail the alkaline phosphatase isoenzyme findings in the largest published series of families with benign familial hyperphosphatasaemia. In each family the propositus had increased plasma intestinal alkaline phosphatase activity, although increases in the activities of the liver and bone isoenzymes were also found in some cases.

Rosalki et al do not state the ABO blood or secretor status of their patients. Inspection of the previously published reports summarised in their paper, however, indicates that in most cases where this information is given, patients were blood group A. This is of interest because plasma intestinal alkaline phosphatase activity is normally lower in those with blood group A than in those with blood group $\mathrm{O}$ or B. ${ }^{2}$ It is also lower in non-secretors of $\mathrm{ABH}$ blood group substance than in secretors ${ }^{34}$ although secretor status is rarely determined in studies of intestinal alkaline phosphatase activity.

We recently identified a family with benign familial hyperphosphatasaemia. The irritable bowel syndrome, who had a very high serum intestinal alkaline phosphatase activity of $250 \mathrm{U} / 1$ (upper reference limit 12 $\mathrm{U} / \mathrm{I})$. Her sister had a similarly increased serum intestinal alkaline phosphatase activity of $290 \mathrm{U} / \mathrm{l}$, and her son had a slightly propositus was a 44 year old woman with increased serum intestinal alkaline phosphatase activity of $46 \mathrm{U} / \mathrm{l}$ (although this was equivocal as he was not fasting when the blood sample was taken). Two daughters had normal serum intestinal alkaline phosphatase activity. The whole family were blood group A. The propositus and her son were secretor positive, but her sister and daughters were secretor negative. The interesting feature of this family was the expression of hyperphosphatasaemia in a blood group A non-secretor subject, and the finding that the serum intestinal alkaline phosphatase activity in this subject was as high as in her secretor positive sister.

The physiological basis of the relation between the ABO blood group system and serum intestinal alkaline phosphatase activity is uncertain. The genes determining ABO blood group encode glycosyltransferase enzymes, and there is a separate gene which determines whether the blood group antigens are secreted in the free form in body fluids. ${ }^{5}$ These glycosyltransferases might modify the carbohydrate moieties of the alkaline phosphatase molecule and therefore change the rate of clearance by carbohydrate binding receptors. ${ }^{6}$ Alternatively, there is evidence that blood group A erythrocytes bind intestinal alkaline phosphatase with high affinity and thereby enhance the rate of clearance from serum. ${ }^{7}$ Whatever the mechanism, blood group specific differences in serum intestinal alkaline phosphatase activity are probably due to differences in the rate of clearance rather than in the rate of synthesis and release of the enzyme. Our finding of benign familial hyperphosphatasaemia with high serum intestinal alkaline phosphatase activity in a blood group A non-secretor subject (who would normally be expected to have very low serum intestinal alkaline phosphatase activity) lends further weight to the suggestion of Rosalki et al that the mechanism underlying this condition may be a mutation affecting a gene controlling the post-translational modification of alkaline phosphatase, or alternatively, that it might affect the function of the reticuloendothelial carbohydrate binding receptors which are responsible for the clearance of intestinal alkaline phosphatase. ${ }^{1}$ It would be interesting to carry out further studies of the kinetics of clearance and erythrocyte binding properties of intestinal alkaline phosphatase in this group of patients.

$$
\begin{array}{r}
\text { AP DAY } \\
\text { Department of Chemical Pathology, } \\
\text { Bristol Royal Infirmary, } \\
\text { Bristol BS2 } 8 H W
\end{array}
$$

1 Rosalki SB, Foo AY, Dooley JS. Benign familial hyperphosphatasaemia as a cause of unexplained increase in plasma alkaline phosphatase activity. $f$ Clin Pathol 1993;46: 738-41.

2 Baileys EM, Seymour PM, Fulton I, Price CP, Luzio JP. A monoclonal antibody capture assay for intestinal alkaline phosphatase ture assay for intestinal alkaline phosphatase and the measurement of this isoenzyme in pregnancy. Clin Chim Acta 1988;172:

3 Arfors KE, Beckman L, Lundin LG. Further studies on the nature between human serum phosphatases and blood groups. Acta phosphatases and blood groups

4 Day AP, Feher MD, Chopra R, Mayne PD. Triglyceride fatty acid chain length influences the post-prandial rise in serum intestinal alkaline phosphatase activity. Ann Clin Biochem 1992;29:287-91.

5 Mollison PL. Blood transfusion in clinical medicine. 7th Edn. Oxford: Blackwell Scientific Publications, 1979. 
6 Komoda T, Sagakishi Y, Sekine T. Multiple forms of human intestinal alkaline phosphatase: chemical and enzymatic properties, phat cheting clearances of the fast- and and circulating clearances 1981;117:167-87.

7 Bayer PM, Hotschek $\mathrm{H}$, Knoth $\mathrm{E}$. Intestinal alkaline phosphatase and the ABO blood group system-a new aspect. Clin Chim Acta group system-

Negative cytology preceding cervical cancer: causes and prevention

I read with interest the article of Robertson and Woodend. ${ }^{1}$ The authors reviewed 140 negative smears from 103 women who subsequently developed cervical cancer ("patients with microinvasive disease were excluded"). Forty eight smears (including one smear with severe inflammatory changes) were negative for abnormal cells $(34.5 \%)$. As the authors consider of importance the "assessment of the quality of the smears received by a laboratory" it is surprising to read that the causes for true false negative smears were not considered.

True false negative smears may result from a series of reasons. Some may be avoided, provided that the patient, and the persons in charge of the collection of the material and of the staining of the smears, are well aware of the pitfalls of the method. In fact, the instrument used for the collection of the smears may in itself entrap atypical cells (figure 1), thus contributing to a false negative smear, ${ }^{2}$ as the atypical cells collected from the area with cervical neoplasia may never reach the slide. The type of instrument used is also important; a significantly lower number of atypical cells are transferred to the slides by cotton swab applicators and plastic spatulas than by cervical brushes. ${ }^{3-5}$ The method by which the smear is handled also has an important role, and variables such as (a) the technique used to deposit the material on to the slide, ${ }^{6}$ (b) the pressure exerted when smearing the material, ${ }^{7}$ and (c) the quality of the cervical mucus ${ }^{7}$ may also influence the presence of atypical cells in a cervical smear. Moreover, during staining procedures, detached material from the slides containing abnormal cells may render smears free from atypical cells, the result being a false negative report. ${ }^{8}$ Also, the detached material may become attached to other slides stained in the same batch (obtained from women without cervical neoplasias). The atypical cells attached to an "innocent" smear may yield a false positive smear. ${ }^{9}$

One other important factor which was not mentioned by Robertson and Woodend is the patient herself. In earlier investigations we showed that smears taken immediately before conisation in cases showing histopathological dysplasia or carcinoma in situ were often negative for atypical cells. ${ }^{10}$ Shortly before taking the smear, the cervico-vaginal area had been thoroughly disinfected with a cotton swab. The vigorous rubbing of the cervix in order to disinfect the surgical area may have removed the superficial layer of atypical cells that are usually collected by conventional techniques of cell sampling. A Swedish gynaecologist found that about one third of his patients had used manual washing deep into the vagina a few hours before examination. Such a washing should have the same effect as the "exfoliation" caused by disinfection before conisation. In some countries the use of vaginal douches is widespread. Thus the patient must be instructed to come to the gynaecologist "unprepared" for a cytological test. One other common finding in smears is the presence of well preserved spermatozoa, suggesting trauma of the cervical mucosa in the hours preceding cell collection (the absence of the spermatozoa, of course, does not rule out coitus). The effect of trauma in removing superficial layers of cervical epithelium has not been sufficiently emphasised.

It is obvious that factors other than the "screening fatigue" mentioned by Robertson and Woodend may be at stake, and that all participants in a cytological examination (the patient herself, midwives, staining tech- nicians, screeners and (alas) even doctors) should receive the proper information and education, so they are aware that each step in the procedure is important to achieve good results.

C A RUBIO

Department of Pathology, Karolinska Institute, 10401 Stockholm, Sweden

1 Robertson JH, Woodend B. Negative cytology preceding cervical cancer: Causes and prevention. $\mathcal{F}$ Clin Pathol 1993;46:700-2.

2 Rubio CA. The false negative smear: II. The trapping effect of collecting instruments. Obstet Gynecol 1977;49:576-80.

3 Rubio CA, Kock Y, Berglund K. Studies of the distribution of abnormal cells in cytologic preparations. I. Making the smear with logic preparations. I. Making the smear with 49-53.

4 Rubio CA, Kock Y, Berglund K, Thomassen $P$. Studies on the distribution of abnorma cells in cytologic preparations. II. Making the smear with a cotton swab applicator. Gynecol Oncol 1980;9:127-34.

5 Rubio CA, Berglund K, Kock Y, Zetterberg A. Studies on the distribution of abnorma cells in cytologic preparations. III. Making the smear with a plastic spatula. Am $\mathcal{f}$ Obstet Gynecol 1980;137:843-6.

6 Rubio CA, Kock Y. Studies on the distribution of abnormal cells in cytologic preparations. $V$. The gradient of cell deposition on slides. Obstet Gynecol 1981;57:754-8.

7 Rubio CA, Stormby N, Kock Y, Thomassen $P$. Studies on the distribution of abnormal cells in cytologic preparations. VI. Pressure exerted by the gynecologist during smearing. Gynecol Oncol 1983;15:391-5.

8 Rubio CA. The false negative smear. $A m f$ Obstet Gynecol 1974;119:273.

9 Rubio CA. The false positive smear. Acta Cytol 1975;19:212-13.

10 Rubio CA. False negatives in cervical cytology: Can they be avoided? Acta Cytol 1981; 25:102.

Drs Robertson and Woodend comment:

Dr Rubio draws attention to potential errors in the screening process mostly related to the taking of smears in the clinic. Our purpose was to deal mainly with the laboratory examination of smears. Dr Rubio is quite correct, however, to emphasise the importance of a good smear-taking technique and other pitfalls described in his many studies.

Cytotoxic activity of Helicobacter pylori enhanced by acetohydroxamic acid

One of the major pathogenicity factors described for Helicobacter pylori is its strong urease activity, which enables it to survive in the acid environment of the stomach. It has therefore been suggested that acetohydroxamic acid (AHA), a potent inhibitor of various bacterial ureases including $H$ pylori urease, ${ }^{1}$ be incorporated into therapeutic regimens aimed at eradicating $H$ pylori. Synergistic effects between AHA and various antimicrobial agents against $H$ pylori in vitro have recently been reported by Phillips et al in this journal, making this approach even more attractive. ${ }^{2}$ As we have observed that AHA enhances the cytotoxic effects produced by $H$ pylori, we would like to add a cautionary note to the discussion on the possible use of AHA for treatment of $H$ pylori infection as suggested by Mooney et $a l^{3}$ and again by Munster et al. . $^{4}$

We have been looking at the cytotoxic effects produced by supernatant fluids of $H$ pylori sonicates on HeLa cells in a quantitative microtitre cytotoxicity assay, performed in a modification of a test described by Gentry et al. ${ }^{5}$ Briefly, sterile filtered $(0.45$
Section of a wooden spatula after collection of cervical material before conisation for carcinoma in situ. Note a large number of normal and atypical squamous cells trapped in the wooden fibres of the spatula (toluidine blue stain) 